\title{
Association between bulk-tank milk Salmonella antibody level and high calf mortality in Danish dairy herds
}

\author{
T. D. Nielsen, ${ }^{1}$ L. R. Nielsen, N. Toft, and H. Houe \\ Department of Large Animal Sciences, University of Copenhagen, 1870 Frederiksberg C, Denmark
}

\begin{abstract}
Salmonella enterica ssp. enterica Dublin is the most common Salmonella serotype found in the dairy sector in Denmark. Salmonella antibody level in bulk-tank milk (BTM), indicative of Salmonella Dublin infection in the herd, has been recorded regularly in all Danish dairy herds through a surveillance program since 2002. The objective of this study was to investigate whether high BTM Salmonella antibody level was associated with high calf mortality at herd level. Other risk factors for high calf mortality were also investigated: breed, production type (organic vs. conventional), number of animals purchased, herd size, and number of neighbor herds within a $4.9-\mathrm{km}$ radius. Data from the Danish Cattle Database including the Salmonella surveillance program from September 2007 through August 2008 were used. Dairy herds with more than 20 cows were included $(\mathrm{n}=4,337)$. Because of a highly right-skewed distribution of calf mortality with many zero values, calf mortality had to be dichotomized for the analysis. Therefore, in this study, high calf mortality was defined as calf mortality of more than $6.5 \%$ for calves aged 1 to 180 d. A logistic analysis was performed to identify risk factors associated with the probability of a herd having high calf mortality. The following factors were significantly associated with high calf mortality: high BTM Salmonella antibody level, odds ratio (OR) $=2.0(95 \%$ confidence interval $=1.6-2.4)$, organic production OR $=1.4(95 \%$ confidence interval $=1.1-1.7)$ for organic versus conventional production, and breed. Purchase of 8 or more animals increased the OR of high calf mortality more than purchase of 1 to 7 animals, which again had a higher OR compared with purchase of 0 animals. Because only $14.3 \%$ of the population consisted of herds with high BTM Salmonella status, the estimated proportion of herds with high calf mortality could only be reduced from 38.7 to $36.5 \%$ by eradicating Salmonella from the Danish cattle population (i.e., a population attributable risk of $2.2 \%$ ). This showed that
\end{abstract}

Received June 30, 2009

Accepted September 20, 2009.

${ }^{1}$ Corresponding author: tdni@life.ku.dk although there is a strong association between BTM Salmonella status and calf mortality, the problem with high calf mortality will not be solved by eradicating Salmonella. All other things equal, a population with more Salmonella-infected herds would gain a larger reduction in calf mortality from a Salmonella control campaign. Nevertheless, individual herds with a high within-herd prevalence of Salmonella are likely to benefit, both economically and regarding animal welfare, from controlling pathogenic Salmonella types in cattle. Key words: Salmonella Dublin, risk factor, calf mortality, dairy cattle

\section{INTRODUCTION}

Mortality in dairy calves aged 1 to $180 \mathrm{~d}$ was, on average, $8.6 \%$ in Denmark in 2007. This was considered a welfare problem, and therefore the Danish Cattle Federation started a campaign to reduce calf mortality to an average of $6.5 \%$ by the end of 2009 .

Salmonella enterica ssp. enterica Dublin (Salmonella Dublin) is host-adapted to cattle (Wray and Sojka, 1977) and can cause both economic losses and reduced welfare in cattle herds through abortions, reproductive problems, and decreased milk yield in adult cows, as well as calf hood disease (Peters, 1985; Visser et al., 1997). Salmonella Dublin primarily affects calves less than 6 mo old (Peters, 1985; Clegg et al., 1986). Clinical signs include diarrhea, fever, dehydration, lethargy, pneumonia, and death. Therefore, controlling Salmonella Dublin might decrease mortality in calves at herd, regional, and national levels.

Salmonella Dublin is endemic in cattle in Denmark with herd seroprevalences ranging from 0 to $30 \%$ in different regions of the country, making it the most common serotype of Salmonella isolated from cattle (Ministry of Food, Agriculture and Fisheries, 2009). The bacteria is introduced to a herd mainly by either purchase of infected animals (Vaessen et al., 1998) or direct contact with infected animals, for example, by sharing pastures (van Schaik et al., 2002). Salmonella Dublin can survive for several years in the environment, which can act as a source of reinfection for the herd (Plym-Forshell and Ekesbo, 1996). 
A national surveillance program was started in 2002 in Denmark to monitor Salmonella status of cattle herds. Since 2007, there has been a campaign in place to encourage eradication of Salmonella Dublin from cattle herds and thus improve animal health and welfare as well as food safety for consumers. Monitoring is based on testing of antibodies directed against Salmonella Dublin lipopolysaccharide antigens $(\mathrm{O}: 9,12)$ in either bulk-tank milk (BTM) for dairy herds or blood for non-milk-producing herds by ELISA (Hoorfar et al., 1995). Other serotypes of Salmonella may cross-react with this antigen (Konrad et al., 1994); hence, Salmonella in this study refers to all serotypes of Salmonella that result in a positive ELISA response. The crossreacting serotype of Salmonella in Denmark is mainly Salmonella Typhimurium. Samples of BTM are collected every $3 \mathrm{mo}$ and a mean value is calculated for the last 4 measurements. Background-corrected optical density value of the sample to a known positive control sample (ODC\%) is calculated and herds are separated into 3 categories in the surveillance program (Ministry of Food, Agriculture and Fisheries, 2003). These categories are publicly available, so farmers have the opportunity to avoid buying animals from farms that are not considered free of Salmonella infection.

Other factors have been reported to affect calf mortality, such as breed (Weigel and Barlass, 2003). Andrews (1999) reported that calves bought into the herd had higher mortality than homebred calves. Furthermore, because Salmonella Dublin is a contagious disease, there is a risk that herd density will affect the distribution of Salmonella-infected herds (Nielsen et al., 2007). No previous studies have examined whether there is an association between BTM Salmonella antibody level and mortality in calves. Nielsen et al. (2007) investigated whether high calf mortality in previous year-quarters could be used as an early indicator of a change in Salmonella status of herds, but found no clear associations.

The objective of this study was to investigate whether there was an association between Salmonella infection in dairy herds (based on BTM antibody testing) and calf mortality during a period of $1 \mathrm{yr}$ while taking into account other possible risk factors for calf mortality such as breed, production type, purchase of animals, herd size, and herd density.

\section{MATERIALS AND METHODS}

\section{Data Sources}

Registry data from the Central Husbandry Register and the Danish Cattle Database (DCD), including data from the National Surveillance Program for Salmonella
Dublin, were collected for this study. These databases are well integrated. All cattle are ear-tagged within a few days of birth and the recording of all movements and deaths is compulsory and reinforced by the European Union's cross-checking and reimbursement systems. Salmonella laboratory results from cattle samples are sent to the DCD from the Danish laboratories.

\section{Study Herds}

Herd was the study unit. In total, 4,488 herds were recorded as milk-producing in Denmark in September 2008. The study population consisted of all Danish dairy herds containing a minimum of 20 cows in August $2008(\mathrm{n}=4,337)$.

\section{Description of Variables}

Variables on risk factors for high calf mortality were constructed from registry data extracted from the DCD. Included risk factors were BTM Salmonella antibody level, breed, production type, number of purchased animals, neighbor herds within a 4.9-km radius, and herd size. Because of skewed distributions, all variables other than herd size were categorized before inclusion in the logistic analysis model as potential risk factors.

BTM Salmonella Antibody Level. This variable was recorded as the mean BTM ODC\% of Salmonella antibody level from September 2007 through August 2008. It was dichotomized using the same cut-off used in the surveillance program, with high BTM Salmonella status being herds with an average $\geq 25$ ODC $\%$ and low BTM Salmonella status being herds with an average $<25$ ODC\% in BTM samples from the study period.

Breed. Breed included all cattle in the herd (all age groups, both sexes, and both dairy and beef cattle). For this study, breed was classified as Jersey if the herd consisted of more than $80 \%$ Jersey animals, large breed if it consisted of more than $80 \%$ large dairy breed animals (primarily Danish Holsteins), and the rest of the herds were classified as mixed breed.

Production Type. Production type was either organic or conventional production as recorded in August 2008 according to the rules for organic production in Denmark. It was assumed to be constant for a herd in the study period.

Purchased Animals. Purchased animals was the number of cattle moved into the herd from September 2007 through August 2008. More than half the herds did not purchase any animals in the study period, but the remaining herds were categorized into 3 approximately equally sized categories, which were 1 to 7,8 to 40 , and $>40$ animals purchased. 
Neighbor Herds Within 4.9 Kilometers. Number of neighbor herds within a $4.9-\mathrm{km}$ radius included all cattle herds (e.g., heifer raising facilities, beef, dairybeef, dairy, hobby, and mixed herds) in August 2008. This distance was used because it was shown previously to be the range that Salmonella status of a herd can influence the status of neighboring herds (Ersbøll and Ersbøll, 2007). The variable for the analysis was categorized into 4 categories of approximately equal size, which were $\leq 25,26$ to 49,50 to 75 , and $>75$ neighbor herds within a $4.9-\mathrm{km}$ radius.

Herd Size. Herd size was recorded as total number of animals in the herd in August 2008. This was a discrete continuous variable.

Calf Mortality. Calculation of calf mortality was based on number of dead calves per day divided by total number of calf days at risk in the herd. If a calf died within $24 \mathrm{~h}$ of birth, it was classified as stillborn and not included in the study. Calf mortality was calculated using the formula below. A calf was censored from the herd if it was sold for export, slaughter, or to another herd. In this case it would not count as being at risk of dying from the day it was removed from the herd. Thus, the probability ( $\mathrm{Pr}$ ) of a calf dying $\mathrm{d} 1$ through 180 was

$$
\begin{aligned}
& \operatorname{Pr}\left(\text { Calf mortality }{ }_{1-180}\right)= \\
& 100 \times\left\{1-\prod_{i=1}^{180}\left(1-\frac{D_{i}}{B+I[<180]-D^{i-1}-C^{i-1}-E[i>1]}\right)\right\},
\end{aligned}
$$

where $D_{i}$ is number of dead or euthanized calves on day $i$; the denominator is number of calves at risk of dying on day $i ; B$ is number of liveborn calves in the study period; and $I[<180]$ is number of calves introduced to herd before $180 \mathrm{~d}$ of age. From this was subtracted calves that died, were killed in the herd, or were censored before the start of day $i . D^{i-1}$ is the sum of dead calves including day $i-1$; if $D^{0}=0$ then $i=1$. $C^{i-1}$ is the sum of censored calves including day $i-1$. $E[i>1]$ is the number of calves euthanized as newborn, which were not deducted until day $i=2$.

Calf mortality was measured in percent and was dichotomized with a cut-off level between high and low in the logistic analysis set to $6.5 \%$. This cut-off is the aim of the campaign initiated by the Danish Cattle Federation.

\section{Statistical Analysis}

Data were analyzed using SAS (version 9.1.3, SAS Institute, Cary, NC). Outlier detection and correlation between variables was assessed using scatter plots and descriptive statistics. A logistic analysis with the dichotomized calf mortality variable as outcome was performed using backward stepwise elimination in PROC GENMOD of SAS (SAS Institute). The main risk factors (BTM Salmonella status, breed, production type, number of purchased animals, herd size, neighbor herds within a $4.9-\mathrm{km}$ radius, and their 2-way interactions) were tested as variables in the model. The criterion for risk factors and interactions to remain in the model was set at $1 \%$ significance level. Nonsignificant interactions were removed first, followed by nonsignificant main effects. After initial reduction of the model, main effects and their 2-way interactions were reinserted one at a time into the model to test for changes in significance by evaluating the $P$-value and confounding by evaluating the changes in estimates for the variables. Furthermore, odds ratios (OR) for risk factors and $95 \%$ confidence intervals were calculated, as well as population attributable risk (PAR) and population attributable fraction (PAF) for BTM Salmonella status. The model was validated by evaluating the goodness of fit-estimate Pearson chi-square value divided by degrees of freedom.

\section{RESULTS}

\section{Descriptive Results}

Of the 4,337 herds originally included in the study, 3 herds consisted of more than $50 \%$ beef cattle but were recorded as dairy herds in the original data set. Four herds had a calf mortality of $100 \%$. However, they had few dead calves relative to the number of cows, most likely because heifers were removed from the premises soon after birth. Thus, the $100 \%$ calf mortalities were misleading numbers. One herd had missing data on calf mortality. Thus, these 8 herds were excluded from the data set. Five herds had no recordings of number of purchased animals, but were kept in the data set.

Another 2 herds were excluded because they were extremely big and not representative in an analysis with herd size as a continuous variable. They consisted of 3,059 and 2,514 animals, respectively. This was much more than the mean herd size of 251 animals in the rest of the data set, and over 1,000 animals more than any other herd. Another 12 herds consisted of more than 1,000 animals. Because there were relatively few large herds, the analysis was performed using herd size as well as herd size truncated at 1,000 animals. When performing the logistic analysis on the full data set, an interaction was found between herd size and purchased animals. It showed that when purchasing more than 40 animals, calf mortality decreased with increasing herd size, whereas calf mortality increased with herd size when purchasing 40 or fewer animals. This interaction 
Table 1. Classification and distribution of categorized variables used for logistic analysis

\begin{tabular}{|c|c|c|c|}
\hline Variable & $\mathrm{n}$ of risk factor & Classification & $\mathrm{n}(\%)$ \\
\hline Low & \multirow[t]{2}{*}{4,327} & $\leq 6.5 \%$ & $2,654(61.3)$ \\
\hline High & & $>6.5 \%$ & $1,673(38.7)$ \\
\hline Low & \multirow[t]{2}{*}{4,327} & $<25$ & $618(14.3)$ \\
\hline High & & $\geq 25$ & $3,709(85.7)$ \\
\hline \multicolumn{4}{|l|}{ Dominant breed } \\
\hline Jersey & 4,327 & $>80 \%$ Jersey & $427(9.9)$ \\
\hline \multirow[t]{2}{*}{ Production type } & \multirow[t]{2}{*}{4,327} & Conventional & $3,908(90.3)$ \\
\hline & & Organic & $419(9.7)$ \\
\hline \multirow[t]{4}{*}{ No. of animals purchased from Sept. 2007 through Aug. 2008} & \multirow[t]{4}{*}{4,322} & 0 & $2,184(50.5)$ \\
\hline & & $1-7$ & $692(16.0)$ \\
\hline & & $8-40$ & $703(16.3)$ \\
\hline & & $>40$ & $743(17.2)$ \\
\hline
\end{tabular}

was not found when removing herds with more than 1,000 animals. Because there were only 12 of these herds, the interaction was considered an artifact of data rather than a biologically plausible effect. Estimates and $P$-values for the other variables did not change when removing these herds. Thus, only 4,315 observations were used for herd size and the interaction was not considered further. Table 1 shows categorized variables used in the logistic analysis and their respective categories together with the distribution of observations in each category.

\section{Analytical Results}

The significant risk factors and significance levels in the final logistic analysis model for high calf mortality are given in Table 2. Breed, BTM Salmonella status, and purchased animals all had $P$-values below 0.0001, whereas production type had a $P$-value of 0.004 .

The OR and $95 \%$ confidence interval for each risk factor in the final model are also given in Table 2. Herds with high BTM Salmonella status had an OR of 2.0 of high calf mortality in the study period compared with herds with low BTM Salmonella status. The highest OR of the study was found for Jersey compared with large breed $(\mathrm{OR}=3.3)$, whereas mixed breed was in between the 2 other breeds $(\mathrm{OR}=1.6)$. Herds where no animals where purchased had the lowest risk of high calf mortality, followed by herds that purchased 1 to 7 animals. There was no difference in calf mortality when purchasing 8 to 40 animals or more than 40 animals,

Table 2. Risk factors associated with calf mortality above $6.5 \%$ in Danish dairy herds at $1 \%$ significance level from September 2007 through August 2008, as well as odds ratios (OR) and 95\% confidence intervals (CI)

\begin{tabular}{|c|c|c|c|c|c|}
\hline Risk factor & Coefficient & $\mathrm{SE}$ & $P$-value & OR & $95 \% \mathrm{CI}$ \\
\hline Bulk-tank milk Salmonella antibody status & & & $<0.0001$ & & \\
\hline High & 0.69 & 0.09 & & 2.0 & $1.7-2.4$ \\
\hline Breed & & & $<0.0001$ & & \\
\hline Jersey $^{c}$ & 1.20 & 0.11 & & 3.3 & $2.7-4.1$ \\
\hline Mixed $^{b}$ & 0.44 & 0.09 & & 1.6 & $1.3-1.9$ \\
\hline Organic & 0.31 & 0.11 & & 1.4 & $1.1-1.7$ \\
\hline Conventional & 0 & 0 & & - & - \\
\hline Purchased animals & & & $<0.0001$ & & \\
\hline$>40^{\mathrm{c}}$ & 0.58 & 0.09 & & 1.8 & $1.5-2.1$ \\
\hline $8-40^{\mathrm{c}}$ & 0.71 & 0.09 & & 2.0 & $1.7-2.4$ \\
\hline $1-7^{\mathrm{b}}$ & 0.24 & 0.09 & & 1.3 & $1.1-1.5$ \\
\hline $0^{\mathrm{a}}$ & 0 & 0 & & - & - \\
\hline
\end{tabular}

${ }^{\mathrm{a}-\mathrm{C}}$ Groups with different superscripts differed significantly $(P<0.01)$.

${ }^{1}$ Dash indicates referent. 
but both groups had significantly higher calf mortality than the 2 groups with few purchases.

The effect of Salmonella herd status on calf mortality at population level was estimated. The PAR was 0.022 for high BTM Salmonella status, which, combined with the prevalence of high BTM status herds (14.3\%), resulted in a PAF of $5.6 \%$. Pearson chi-square value divided by degrees of freedom was 1.0017, suggesting a good fit for the final model.

\section{DISCUSSION}

\section{Main Findings}

This study showed an overall association between calf mortality in dairy herds and BTM Salmonella status, production type, breed, and number of purchased animals.

High BTM Salmonella status, indicative of Salmonella Dublin infection, was associated with increased risk of high calf mortality in dairy herds. Others have found increased calf mortality with clinical salmonellosis (Lance et al., 1992a; Rice et al., 1997). Gay and Hunsaker (1993) isolated multiple Salmonella serovars from a dairy herd $2 \mathrm{yr}$ after clinical symptoms of salmonellosis had ceased. This herd had high calf mortality (54 of 308 heifer calves died), but the study did not show whether this was a result of Salmonella being present in the herd. In another study, clinical disease was not observed in a dairy herd where Salmonella Dublin was isolated from BTM (Anderson et al., 2001).

The Jersey breed was found to be associated with high calf mortality. Weigel and Barlass (2003) let farmers score the calf mortality for Jerseys, Holsteins, and cross-breeds, and farmers gave Jerseys the highest mortality score. Increased number of purchased animals had an association with calf mortality. In this study, it was not possible to distinguish which animals were purchased (age, sex, and so on), but Andrews (1999) found that purchased calves had higher mortality than homebred calves. We found no association between calf mortality and herd size, which corresponded with what others have found previously (Martin et al., 1975; Mee et al., 2008). Gulliksen et al. (2009) found increasing calf mortality with increasing herd size, but they investigated Norwegian dairy herds, which on average are much smaller than Danish herds.

The study showed that, taking into account the differences in calf mortality between different breeds, production types, and purchase patterns, the risk of high mortality that was attributed to high BTM Salmonella status was $2.2 \%$ (PAR). Hence, if all dairy herds would achieve low BTM Salmonella status, we would expect the proportion of herds with calf mortality above $6.5 \%$ to decrease from 38.7 to $36.5 \%$ under conditions where $14.3 \%$ of the herds were infected with Salmonella, as in this study. The PAF value suggested that $5.6 \%$ of the herds in the dairy herd population had a high mortality as a result of some herds having high BTM Salmonella status. This shows that eradication of Salmonella from dairy herds is likely to decrease calf mortality to some extent (both at herd level and at national level) but, because of the low prevalence of Salmonella, it is unlikely to reduce calf mortality noticeably at national level. This study investigated mainly endemic Salmonella Dublin infection in the herds. The benefit of Salmonella control may be higher in higher prevalence regions or herds with clinical outbreaks.

\section{Statistical Analysis}

The nature of the data suggested an ANOVA as best choice of analytical method. However, calf mortality was not normally distributed as a continuous variable and the herds with zero mortality for calves $(12 \%$ of the study population) had to be removed to perform an ANOVA. Even without these observations, assumptions of normal distribution could not be fulfilled and so data were dichotomized and analyzed by logistic analysis. To underline the logic in using categorical variables, an attempt was made to find natural cut-off values (e.g., breed, purchased animals) or values used elsewhere in official programs (e.g., BTM Salmonella status, calf mortality).

The logistic analysis was performed at 5 different cutoffs for calf mortality (data not shown): $2.3 \%$ (the $25 \%$ quartile for the study data), $2.9 \%$ (the $25 \%$ quartile for Danish dairy herds), $10 \%,<5 \%$ compared with $>10 \%$, and $6.5 \%$ (aim of calf mortality campaign). Main risk factors found to be significant in the final models were identical at all cut-off levels except production type, which had significance levels between 0.05 and $2 \%$, depending on the cut-off level. This led us to conclude that the model was robust with respect to cut-off for calf mortality and, thus, that our findings represented real effects rather than artifacts of the chosen method of analysis.

\section{Data Quality and Availability}

This study was based solely on registry data. These contain information on all herds in Denmark, which gives a unique opportunity to evaluate risk factors for calf mortality at herd level. Because Salmonella is a contagious disease, observations at herd level were needed to assess the risk factors. However, the use of registry data excluded the possibility of including factors related to management such as grazing, treat- 
ments, calving management, hygiene, barn structures, and so on, which limited the conclusions that could be made. Calf management has been found to affect calf mortality (Lance et al., 1992b; Losinger and Heinrichs, 1997). Lance et al. (1992b) found that housing type and dipping of navels with disinfectant affected the mortality of preweaned calves. It could improve the model if management practices were included. However, we were not able to assess management of calves from the registry data. Fossler et al. (2005a,b) investigated associations between SCC and production level measured as rolling herd average on Salmonella shedding in calves and cows. These measures can be seen as indirect measures of management of the herds. They found no association between SCC and shedding, but found that production level was associated with shedding of Salmonella in calves but not in cows. The effect of Salmonella herd status on calf mortality may to some extent be explained by underlying management and hygiene factors, and organic producers are subjects to rules that lead to different management than in conventional herds, in particular regarding feed, medication, and contact between individual animals in the herd.

Farmers themselves had to record dead calves, so there was a risk of errors in the calf mortality data. However, recordings of dead animals are accurate in Denmark because all dead animals have to undergo destruction and destruction centers record which animals they receive. Very few herds $(\mathrm{n}=10)$ had to be removed from the data set because of missing or unrealistic recordings. A total of 6 missing values were found among the different variables. This study contained 4,337 out of 4,488 Danish dairy herds, and the study population can be assumed to be representative of dairy herds in Denmark.

\section{Salmonella Herd Classification}

Bulk-tank milk Salmonella status is an indirect measure of infection in the herd. Misclassification could have biased the results of the model. In 2007, Salmonella Dublin accounted for $52 \%$ of Salmonella serotypes isolated from dairy herds in Denmark, and it has the potential to persist longer in the herds than other types of Salmonella (Boqvist and Vågsholm, 2005). However, results for this study included other types of Salmonella because there was a risk of cross-reaction in the testing program (Konrad et al., 1994). Warnick et al. (2006) evaluated the classification accuracy of the surveillance program. They found that at a prevalence of $15 \%$ Salmonella positive herds in the study population, the negative predictive value for category 1 (expected free of Salmonella) was estimated to be $99 \%$, whereas the positive predictive value for category 2 (possibly Salmonella infected) was estimated to be $80 \%$. The surveillance program is constructed to ensure that herds classified as Salmonella-free really are free. The high negative predictive value means that only $1 \%$ of herds classified as category 1 are likely to be false negative. However, the low positive predictive value means that around $20 \%$ of herds classified as possibly Salmonellainfected could be free of infection. This may have led to underestimation of the association between high BTM Salmonella status and high calf mortality in this study if herds wrongly classified had low calf mortality, or overestimation of the association if herds wrongly classified had high calf mortality.

It was not possible to estimate the number of calves that could be saved on a national level by eradicating Salmonella Dublin because the outcome of the model is percent calf mortality at herd level and because we do not know the exact distribution of other serotypes in the population. The number of calves that can be saved on a yearly basis is probably fairly limited as expressed by the PAR. However, individual herds with a high within-herd prevalence of Salmonella are likely to benefit, both economically and regarding animal welfare, from controlling pathogenic Salmonella-types.

\section{ACKNOWLEDGMENTS}

The authors thank Jørgen Nielsen and Peter Stamp Enemark from Danish Cattle Federation (Aarhus, Denmark) for providing data.

\section{REFERENCES}

Anderson, R. J., J. K. House, B. P. Smith, H. Kinde, R. L. Walker, B. J. Vande Steeg, and R. E. Breitmeyer. 2001. Epidemiologic and biological characteristics of salmonellosis in three dairy herds. J. Am. Vet. Med. Assoc. 219:310-322.

Andrews, A. H. 1999. Calf mortality. Cattle Pract. 7:45-47.

Boqvist, S., and I. Vågsholm. 2005. Risk factors for hazard of release from Salmonella-control restriction on Swedish cattle farms from 1993 to 2002. Prev. Vet. Med. 30:35-44.

Clegg, F. G., C. Wray, A. L. Duncan, and W. T. Appleyard. 1986. Salmonellosis in two dairy herds associated with a sewage farm and water reclamation plant. J. Hyg. (Lond.) 97:237-246.

Ersbøll, A. K., and B. K. Ersbøll. 2007. Improving semivarigram estimates by means of regional polish and robust estimation in the case of spread of Salmonella Dublin between irregular spaced cattle herds. In Proceedings Gisvet Conference, Copenhagen, Denmark. University of Copenhagen, Denmark.

Fossler, C. P., S. J. Wells, J. B. Kaneene, P. L. Ruegg, L. D. Warnick, J. B. Bender, L. E. Eberly, S. M. Godden, and L. W. Halbert. 2005a. Herd-level factors associated with isolation of Salmonella in a multi-state study of conventional and organic dairy farms: I. Salmonella shedding in cows. Prev. Vet. Med. 70:257-277.

Fossler, C. P., S. J. Wells, J. B. Kaneene, P. L. Ruegg, L. D. Warnick, J. B. Bender, L. E. Eberly, S. M. Godden, and L. W. Halbert. 2005b. Herd-level factors associated with isolation of Salmonella in a multi-state study of conventional and organic dairy farms: II. Salmonella shedding in calves. Prev. Vet. Med. 70:279-291. 
Gay, J. M., and M. E. Hunsaker. 1993. Isolation of multiple Salmonella serovars from a dairy two years after a clinical salmonellosis outbreak. J. Am. Vet. Med. Assoc. 203:1314-1320.

Gulliksen, S. M., K. I. Lie, T. Loken, and O. Osteras. 2009. Calf mortality in Norwegian dairy herds. J. Dairy Sci. 92:2782-2795.

Hoorfar, J., P. Lind, and V. Bitsch. 1995. Evaluation of an O antigen enzyme-linked immunosorbent assay for screening of milk samples for Salmonella Dublin infection in dairy herds. Can. J. Vet. Res. 59:142-148.

Konrad, H., B. P. Smith, G. W. Dilling, and J. K. House. 1994. Production of Salmonella serogroup D (O9)-specific enzyme-linked immunosorbent assay antigen. Am. J. Vet. Res. 55:1647-1651.

Lance, S. E., G. Y. Miller, D. D. Hancock, P. C. Bartlett, and L. E. Heider. 1992a. Salmonella infections in neonatal dairy calves. J. Am. Vet. Med. Assoc. 201:864-868.

Lance, S. E., G. Y. Miller, D. D. Hancock, P. C. Bartlett, L. E. Heider, and M. L. Moeschberger. 1992b. Effects of environment and management on mortality in preweaned dairy calves. J. Am. Vet. Med. Assoc. 201:1197-1202.

Losinger, W. C., and A. J. Heinrichs. 1997. Management practices associated with high mortality among preweaned dairy heifers. J. Dairy Res. 64:1-11.

Martin, S. W., C. W. Schwabe, and C. E. Franti. 1975. Dairy calf mortality rate: Influence of management and housing factors on calf mortality rate in Tulare County, California. Am. J. Vet. Res. 36:1111-1114.

Mee, J. F., D. P. Berry, and A. R. Cromie. 2008. Prevalence of, and risk factors associated with, perinatal calf mortality in pasturebased Holstein-Friesian cows. Animal 2:613-620.

Ministry of Food, Agriculture and Fisheries. 2003. Annual Report on Zoonoses in Denmark 2002. Ministry of Food, Agriculture and Fisheries, Copenhagen, Denmark.

Ministry of Food, Agriculture and Fisheries. 2009. Annual Report on Zoonoses in Denmark 2007. Ministry of Food, Agriculture and Fisheries, Copenhagen, Denmark.
Nielsen, L. R., L. D. Warnick, and M. Greiner. 2007. Risk factors for changing test classification in the Danish surveillance program for Salmonella in dairy herds. J. Dairy Sci. 90:2815-2825.

Peters, A. R. 1985. An estimation of the economic impact of an outbreak of Salmonella Dublin in a calf rearing unit. Vet. Rec. 117:667-668.

Plym-Forshell, L., and I. Ekesbo. 1996. Survival of salmonellas in urine and dry faeces from cattle-An experimental study. Acta Vet. Scand. 37:127-131.

Rice, D. H., T. E. Besser, and D. D. Hancock. 1997. Epidemiology and virulence assessment of Salmonella Dublin. Vet. Microbiol. $56: 111-124$.

Vaessen, M. A., J. Veling, K. Frankena, E. A. M. Graat, and T. Klunder. 1998. Risk factors for Salmonella Dublin infection on dairy farms. Vet. Q. 20:97-99.

van Schaik, G., Y. H. Schukken, M. Nielen, A. A. Dijkhuizen, H. W. Barkema, and G. Benedictus. 2002. Probability of and risk factors for introduction of infectious diseases into Dutch SPF dairy farms: A cohort study. Prev. Vet. Med. 54:279-289.

Visser, S. C., J. Veling, A. A. Dijkhuizen, and R. B. M. Huirne. 1997. Economic losses due to Salmonella Dublin in dairy cattle. Pages 143-151 in Proc. Dutch/Danish Symp. Anim. Health Manage. Economics, Copenhagen, Denmark. A. R. Kristensen, ed. Royal Veterinary and Agricultural University, Frederiksberg, Denmark.

Warnick, L. D., L. R. Nielsen, J. Nielsen, and M. Greiner. 2006. Simulation model estimates of test accuracy and predictive values for the Danish Salmonella surveillance program in dairy herds. Prev. Vet. Med. 77:284-303.

Weigel, K. A., and K. A. Barlass. 2003. Results of a producer survey regarding crossbreeding on US dairy farms. J. Dairy Sci. 86:41484154 .

Wray, C., and W. J. Sojka. 1977. Reviews of the progress of dairy science: Bovine salmonellosis. J. Dairy Res. 44:383-425. 